\title{
Clinical and Molecular Characterization of Ataxia with Oculomotor Apraxia Patients In Saudi Arabia
}

\author{
Saeed A Bohlega ${ }^{1 \dagger}$, Jameela M Shinwari ${ }^{2+}$, Latifa J Al Sharif², Dania S Khalii², Thamer S Alkhairallah',
} Nada A Al Tassan²

\begin{abstract}
Background: Autosomal recessive ataxias represent a group of clinically overlapping disorders. These include ataxia with oculomotor apraxia type1 (AOA1), ataxia with oculomotor apraxia type 2 (AOA2) and ataxia-telangiectasia-like disease (ATLD). Patients are mainly characterized by cerebellar ataxia and oculomotor apraxia. Although these forms are not quite distinctive phenotypically, different genes have been linked to these disorders. Mutations in the APTX gene were reported in AOA1 patients, mutations in SETX gene were reported in patients with AOA2 and mutations in MRE11 were identified in ATLD patients. In the present study we describe in detail the clinical features and results of genetic analysis of 9 patients from 4 Saudi families with ataxia and oculomotor apraxia.

Methods: This study was conducted in the period between 2005-2010 to clinically and molecularly characterize patients with AOA phenotype. Comprehensive sequencing of all coding exons of previously reported genes related to this disorder (APTX, SETX and MRE11).
\end{abstract}

Results: A novel nonsense truncating mutation c.6859 C > T, R2287X in SETX gene was identified in patients from one family with AOA2. The previously reported missense mutation W210C in MRE11 gene was identified in two families with autosomal recessive ataxia and oculomotor apraxia.

Conclusion: Mutations in APTX, SETX and MRE11 are common in patients with autosomal recessive ataxia and oculomotor apraxia. The results of the comprehensive screening of these genes in 4 Saudi families identified mutations in SETX and MRE11 genes but failed to identify mutations in APTX gene.

\section{Background}

Ataxia with Oculomotor Apraxia (AOA) is an autosomal recessive cerebellar ataxia (ARCA) mainly characterized by ataxia, oculomotor apraxia and choeroathetosis [1]. Two clinically overlapping forms were characterized; AOA1 (MIM\# 208920) and AOA2 (MIM\# 606002). Patients with AOA1 present with cerebellar ataxia and oculomotor apraxia between ages 2 and 18 years old [2] accompanied later in life by limb dysmetria and sensory-motor neuropathy which may be associated with dystonia or mental retardation, hypoalbuminemia, hypercholesterolemia and normal immunoglobulins and alpha-fetoprotein levels. There is no evidence of chromosomal instability and no reported tumor predisposition in these patients [3].

\footnotetext{
* Correspondence: naltassan@kfshrc.edu.sa

+ Contributed equally

${ }^{2}$ Department of Genetics, King Faisal Specialist Hospital and Research Center. P.O box 3354 Riyadh 11211 Saudi Arabia

Full list of author information is available at the end of the article
}

Patients with AOA2 present with gait ataxia, cerebellar atrophy, sensory-motor neuropathy, ocular-motor apraxia and elevated immunoglobulins and alpha-fetoprotein levels with an age of onset (10-22years)[4]. In addition patients with Ataxia-Telangiectasia-Like Disorder (ATLD also known as MRE11 ataxia MIM\# 604391) present with early onset ataxia and oculomotor apraxia [5]

Although these forms may not be quite distinctive phenotypically, they are genetically heterogeneous. Mutations in the APTX gene located on chromosome 9 p13.3 were identified in patients with AOA1. These include; missense, nonsense, splice mutations, single base insertions and deletions [2,6-9]. A deletion of the whole $A P T X$ ORF was reported in one family with AOA1 phenotype [6]. Most mutations were clustered between codons 198-280. Moreover; recurrent mutations were reported in some populations; (689insT, P206L) in Japanese patients and (W279X) in Portuguese 
families [6]. The APTX gene encodes a histidine-triad (HIT) protein known as aprataxin [8].

Aprataxin is a nuclear protein of three domains; a forkhead-associated (FHA) domain that mediates proteinprotein interaction with molecules that respond to DNA damage such as binding to DNA single strand break repair scaffold protein (XRCC1) and binding to DNA double strand break repair scaffold protein (XRCC4). Aprataxin also contains a histidine triad (HIT) domain and a $\mathrm{COOH}$ terminal zinc finger domain $[7,8,10,11]$, the HIT domain is similar to Hint, a universal conserved AMP-lysine hydrolase, studies showed that Aprataxin has an active site dependent AMP lysine and GMP lysine hydrolase activity that also depends on the zinc finger for protein stability and on the FHA domain for enzyme activity [11].

A number of missense, nonsense and frameshift mutations in the SETX gene located in 9q34 were identified in patients with AOA2 and a duplication covering exons 710 was also identified in a patient with AOA2 [12,13]. SETX gene is also mutated in the autosomal dominant form of juvenile amyotrophic lateral sclerosis (ALS4) and tremor/ataxia syndrome $[14,15]$. Most reported mutations in AOA2 patients were clustered in exons 6 and 8 and a common hot spot mutation at codon 1363 resulting in a change from amino acid arginine to a truncating codon was recurrent in families from Portugal, Cabe Verde and Spain [12]. Senataxin, the product of SETX is a 2677 amino acid protein which harbors a C-terminus 7-motif domain (DNA/RNA helicase domain) found in helicases superfamily1, suggesting that senataxin my play a role in DNA repair $[12,16]$. Mutations in one of the MRN complex genes; MRE11 located in 11q21 were reported in patients with ATLD $[5,17,18]$. In the current study we describe the clinical phenotypes and molecular characterization of 9 patients with autosomal recessive ataxia and oculomotor apraxia from 4 unrelated consanguineous families. We identified a novel truncating mutation $\mathrm{R} 2287 \mathrm{X}$ in SETX in one family in addition to the previously reported mutation W210C in MRE11 gene in two families. These findings emphasize on the role of these genes in such disorders.

\section{Methods}

\section{Families and samples}

This study was ethically approved (RAC\#2050036) and conducted in the period between 2005-2010 at King Faisal Special hospital and Research Center (KFSHRC) which is a major tertiary care hospital in Saudi Arabia. The medical records databases were requested to provide us with all patients diagnosed with ataxia and/or oculomotor apraxia. We were able to identify and enroll four families ( 9 affected individuals) from the central and western regions of Saudi Arabia presented with clinical features that falls within Ataxia Oculomotor Apraxia spectrum. Consanguinity is a major feature in all these families. Clinical details of patients are summarized in Table 1 and pedigrees are presented in Figure 1. Further details on these families are described below:

Family A: two sisters aged 27 (IV:1) and 23 (IV:3) were examined, age of onset 14 and 20 years respectively; parents were related, the other three siblings were normal. Only the elder sister had clear oculomotor apraxia, very slow horizontal saccadic ocular movement, vertical saccads were minimally affected, smooth pursuit ocular movement were poor in all directions. Frequent head thrusts were noted, tendon reflexes were absent and sensor nerve action potentials were reduced while alphaphetoprotein was elevated.

Family B: Parents were first cousins. One male aged 33 (II:2)and one female aged 31 (II:3)were examined the remaining four siblings were normal. Progressive ataxia started at ages 15 and 17 years and patients were still ambulatory with difficulty at the stated age. Vertical more than horizontal oculomotor apraxia was noted with absent voluntary vertical eye movement and intact oculocephalic reflex. In addition both patients had cognitive and behavioral problem with forgetfulness, lack of attention, word finding difficulty, emotional liability, impulsivity and disinhibition with fragmented and reversed sleep patterns. Tendon reflexes and normal nerve conduction studies were normal. EEG was diffusely dysarythmic. Brain MRI showed no cerebellar atrophy.

Family C: Parents were second-degree cousins, 25 years old sister (II:1) and 23 years old brother (II:2) were examined, and one niece was similarly affected (not examined). Gait and limb ataxia were noted around 2-3 years of age, ocular apraxia started around age of 10 years, smooth pursuit ocular movement was absent in all directions and saccadic eye movement was also defective. Small saccads were substituting for the large one and required head thrusts. Brain MRI showed severe cerebellar atrophy and Brain FDG-PET showed cerebellar hypometabolism. Decreased vibration sense was noted distally, and axonal mainly sensory polyneuropathy was observed with nerve conduction study.

Family D: Parents were first cousins. Three affected individuals, $30(\mathrm{~V}: 1), 27(\mathrm{~V}: 2)$ and $16(\mathrm{~V}: 7)$ years old were examined. Five other nephews and nieces were historically affected but not studied. Ataxia was noted at age two years and oculomotor apraxia was variable among the affected individuals with very slow saccadic eye movement and impaired horizontal more than vertical pursuit eye movement with head thrusts. Vibration senses were decreased distally and tendon reflexes were absent. There was no cognitive impairment. Dystonic and choreatic movement were frequently noted. 
Table 1 Clinical and biochemical characteristics of AOA patients participated in the study

\begin{tabular}{|c|c|c|c|c|c|c|c|c|c|}
\hline \multirow[b]{2}{*}{ Patient } & \multicolumn{2}{|c|}{ Family A } & \multicolumn{2}{|c|}{ Family B } & \multicolumn{2}{|c|}{ Family C } & \multicolumn{3}{|c|}{ Family D } \\
\hline & IV.1 & IV3 & 11.2 & 11.3 & 11.1 & 11.2 & V.1 & V.2 & V.7 \\
\hline Sex & $\mathrm{F}$ & $\mathrm{F}$ & $M$ & $\mathrm{~F}$ & $\mathrm{~F}$ & $M$ & $M$ & $\mathrm{~F}$ & $F$ \\
\hline Age & 27 & 23 & 33 & 31 & 25 & 23 & 30 & 27 & 16 \\
\hline Age of onset & 14 & 20 & 15 & 17 & 3 & 2 & 2 & 3 & 2 \\
\hline Ataxia & +++ & ++ & ++ & +++ & ++ & + & ++ & +++ & +++ \\
\hline Ocular Apraxia & ++ & NP & + & + & ++ & +++ & ++ & + & + \\
\hline Dysarthria & + & NP & + & + & ++ & + & + & + & NP \\
\hline Mental subnormality & $\mathrm{NP}$ & NP & ++ & ++ & + & + & NP & NP & $\mathrm{NP}$ \\
\hline Cerebellar atrophy & ++ & ++ & $\mathrm{NP}$ & NP & ++ & ++ & ++ & ++ & ++ \\
\hline Tendon reflexes & Absent & Absent & Normal & Normal & Absent & Absent & Absent & Absent & Absent \\
\hline Nerve conduction study & $\begin{array}{l}\text { Axonal } \\
\text { poly. }\end{array}$ & $\begin{array}{l}\text { Axonal } \\
\text { poly. }\end{array}$ & Normal & Normal & $\begin{array}{l}\text { Axonal } \\
\text { poly. }\end{array}$ & $\begin{array}{l}\text { Axonal } \\
\text { poly. }\end{array}$ & Normal & Normal & Normal \\
\hline AFP (n 0-15) & 24.4 & 51.0 & 2.0 & 1.8 & 3.5 & 2.5 & 4.3 & 4.2 & 4.1 \\
\hline Gene/Mutation & \multicolumn{2}{|c|}{ SETX/R2287X } & \multicolumn{2}{|c|}{ MRE11/W210C } & \multicolumn{2}{|c|}{$\begin{array}{l}\text { No mutations in } \\
\text { APTX, SETX, MRE11 }\end{array}$} & \multicolumn{3}{|c|}{ MRE11/W210C } \\
\hline
\end{tabular}

M male, F female, NP Not present, + mild, ++ moderate, +++ severe.

A)

Family A

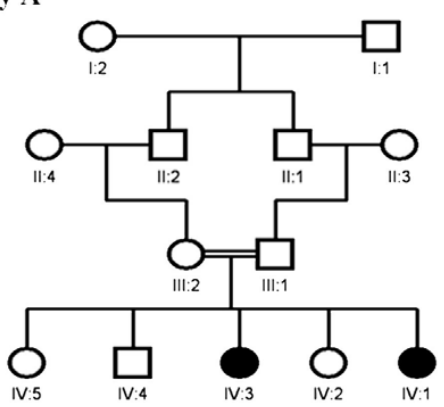

C)

Family C

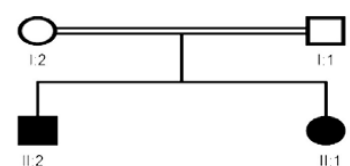

B)

Family B

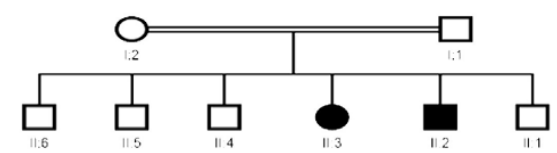

D)

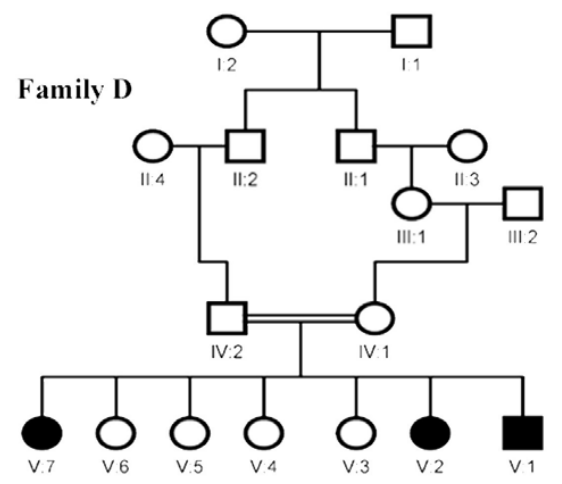

Figure 1 Pedigrees of AOA1 and AOA2 families. Each family has at least two affected individuals and autosmal recessive mode of inheritance. 
The disease was relentlessly progressive and patients became wheelchair-bound around age of 18 years. Intrafamilial variability was noticeable with the middle patient more severely affected.

\section{Samples}

Blood samples were obtained with informed consent from family members in adherence with institutional and international guidelines (RAC\#2050036). DNA was extracted from $3 \mathrm{ml}$ of whole blood using Gnetra systems according to manufacturer conditions. DNA concentrations were determined.

\section{Amplification and sequence of APTX, SETX and MRE11 genes}

The coding exons and flanking intronic sequences of APTX, SETX and MRE11 genes were amplified (primers are available upon request). PCRs were performed in a $25 \mu \mathrm{l}$ reaction volume containing $2.5 \mu \mathrm{l}$ of $10 \times$ reaction buffer (15 mM $\mathrm{MgCl}_{2}$,), $0.2 \mathrm{mM}$ dNTPs, $10 \mu \mathrm{M}$ of ARMS primers, $5 \mu \mathrm{M}$ of IC primers, $1 \mathrm{U}$ of HotStarTaq polymerase (QIAgen), and $10 \mathrm{ng}$ genomic DNA. Cycling parameters were $94^{\circ} \mathrm{C}$ for $10 \mathrm{~min}, 30-35$ cycles of $94^{\circ} \mathrm{C}$ for $45 \mathrm{sec}, 52-59^{\circ} \mathrm{C}$ for $45 \mathrm{sec}$ and $72^{\circ} \mathrm{C}$ for $45 \mathrm{sec}$ followed by a final elongation step at $72^{\circ} \mathrm{C}$ for $10 \mathrm{~min}$. Products were visualized on ethidium bromide stained agarose gels.

PCR products were sequenced using ABI Prism Big Dye ${ }^{\mathrm{TM}}$ Terminator ready reaction cycle sequencing kit (Applied Biosystems). Products were electrophoresed using automated ABI DNA sequencer. Sequencing results were exported in one of several formats for visualization and analysis of sequence using Lasergene 6 software package.

\section{Microsatellite Analysis}

Microsatellite markers flanking APTX (D9S83, D9S1788, D9253) and SETX (D9S1861, D9S179, D9S1847, D9S2127) were used for further genotype analysis. PCR was performed using $0.24 \mathrm{uM}$ primers (forward primer FAM labeled), $2.5 \mathrm{mM}$ dNTP, $10 \times$ buffer and 1 Unit of Taq polymerase and $10 \mathrm{ng}$ of DNA in a 10 ul reaction. Products were run on a MegaBace 1000 capillary sequencer. Results were analyzed using MegaBase Genetic profiler V.2 (Amersham Biosciences).

\section{Linkage analysis}

10K SNP genotyping was performed as detailed by Affymetrix on the GeneChip ${ }^{\circledR}$ Human Mapping 10K Array Xba 142 2.0. In summary, 50ng of genomic DNA was digested with 10 units of $\mathrm{XbaI}$ (New England Biolabs, MA) for 2 hours at $37^{\circ} \mathrm{C}$. T4 DNA Ligase was used to ligate the Xba Adaptor (Affymetrix, CA) to the digested ends. The ligated samples were diluted with water and were used as PCR templates for primers specific to the adaptor sequence with the following cycling parameters: $95^{\circ} \mathrm{C}$ for 3 minutes initial denaturation, $95^{\circ} \mathrm{C} 20$ seconds, $62.5^{\circ} \mathrm{C} 15$ seconds, $72^{\circ} \mathrm{C} 15$ seconds for a total of 35 cycles, followed by $72^{\circ} \mathrm{C}$ for 7 minutes final extension. PCR products were then purified with salt precipitation and fragmented at $37^{\circ} \mathrm{C}$ for 45 minutes. The fragmented DNA was then end-labeled with biotin using 1.5 units of terminal deoxynucleotide transferase (TD) the reaction was incubated at $37^{\circ} \mathrm{C}$ for 2 hours. Labeled DNA was then hybridized onto the $10 \mathrm{~K}$ Mapping Array DNA Chip at $48^{\circ} \mathrm{C}$. The hybridized array was washed, stained, and scanned according to the manufacturer's instructions.

SNP genotypes were generated using affymetrix GCOS 1.4 software. Multipoint LOD score was performed with easy linkage software package.

\section{Results}

\section{Mutations in SETX gene}

A novel truncating mutation (c.6859 C > T, R2287X) in exon 20 of the SETX gene was identified as the disease causing mutation in family A. All affected individuals were homozygous for this mutation while other family members were heterozygous carrying both wild-type and mutant allele (Figure 2).

\section{Variants Identified in SETX and APTX genes}

A total of 11 missense, silent and intronic variants were identified in both genes. These include APTX c836+91t > c. SETX c846+20a > g, 846+30t > c, T1855A, D1937, $\mathrm{T} 2587 \mathrm{~V}$ and the previously reported variants in SETX

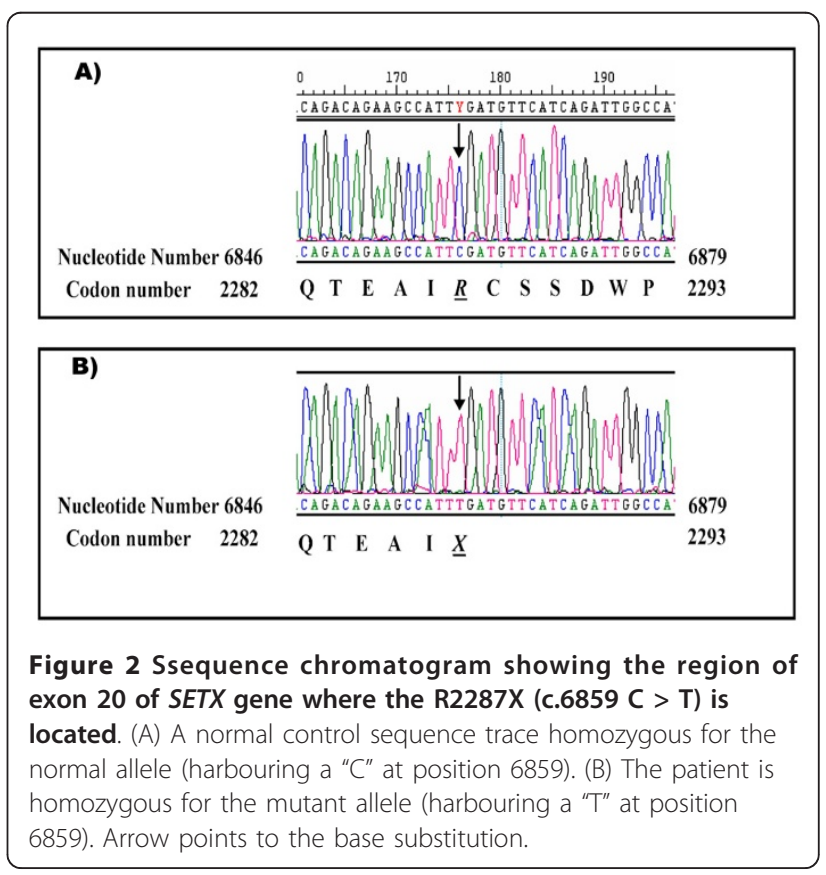


gene Y359, H1049, D1192E, G1252R and I1385V[12]. None of these variants segregated with the disease in families B and C.

\section{Haplotype analysis in Family D}

Haplotype results using both microsatellite and intragenic markers excluded both APTX and SETX genes as the underlying genetic cause in this family.

\section{Linkage analysis}

linkage analysis on family D revealed a disease locus in $4 \mathrm{Mb}$ regions on the long arm of chromosome 11 with a maximum multipoint logarithm of odds (LOD) score of 3.2 harboring MRE11 gene.

\section{Mutations in MRE11 gene}

Sequencing analysis identified a previously reported missense mutation in exon 7 of MRE11 gene (c.630 G > C, W210C) in family D. This mutation was also identified in affected individuals from family B (Figure 3 ).

\section{Discussion}

Inherited diseases of the nervous system are medically and genetically heterogeneous group of abnormalities. Mutations in LMNA, GAN1, KCC3, TDP1, APTX, SETX and MRE11 were found to be the causes of autosomal recessive axonal neuropathies [19-21]. Ataxia with Oculomotor Apraxia type1 (AOA1), Ataxia with Oculomotor Apraxia type2 (AOA2), Ataxia with Oculomotor Apraxia type3 (AOA3), Ataxia Talengestasia (AT) and Ataxia Talengestasia Like (ATLD) represent a group of overlapping recessively inherited ataxias[22]. APTX and SETX gene mutations were identified in patients with AOA1

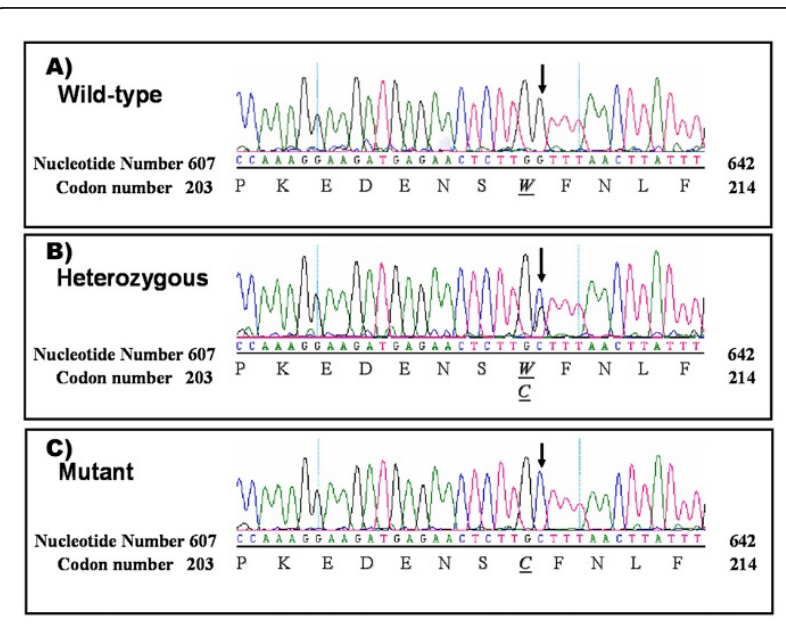

Figure 3 Exon 7 of MRE11 gene sequence showing the location of W210C (c.630 G > C) mutation. (A) Wild type sequence. (B) Heterozygous (C) Homozygous for the mutant allele. Arrow points to the base substitution. and AOA2 from different populations, indicating that these genes represent the common underlying genetic cause for AOA in these patients. In this study, a novel homozygous truncating mutation R2287X in SETX gene was identified in the 3 affected individuals in Family A. The SETX gene codes for senataxin, a protein that contains a DNA/RNA helicase and is involved in DNA repair.

Most reported mutations in SETX were present in exon 8 resulting in loss of the $C$ - terminus motifs but this mutation is localized in exon 20 of the gene resulting in a protein that retains the $\mathrm{C}$ terminus helicase domain, thereby indicating the importance of other domains.

Such domains could possibly be involved in the interaction with other proteins involved in transcription and RNA processing including RNA polymeraseII, suggestive of an additional role for senataxin in the coordination of different transcription events[23].

Three Saudi families from consanguineous marriages with ataxia and oculomotor apraxia were enrolled in this study (Table 1). Although AOA1 affected individuals with mutations in APTX have been identified world wide; 13 individuals from 3 unrelated Tunisian family [6], 2 unrelated individuals from Germany [24], 3 unrelated Italian individuals [25], 2 American children [26] and 4 Caucasians with ataxia and CoQ10 deficiency [27], yet comprehensive screening by direct sequencing of the APTX gene did not identify any mutations in these 3 Saudi families. Microsatellite analysis further excluded this gene as disease causing in these families. However, linkage analysis on family D with 3 affected individuals identified a locus harboring MRE11 gene which is mutated in ATLD where there is progressive cellular degeneration, ocular apraxia and absence of ocular telangiectasia $[17,18,28]$. Sequencing of MRE11 in family D members identified the previously reported W210C missense mutations in all affected individuals from both families B and D. W210C missense mutation was identified in 10 Saudi patients with ATLD [5]. Some studies suggested that the signaling related function of the MreII/Rad50/Nbs1 (MRN) complex is related to the ATM function in mammalian cells, as certain components of the MRN complex act substrates for ATM which is in turn important for $\mathrm{S}$ phase checkpoint activation and cell survival following double-strand breaks [29]. Screening all these genes in affected individuals of family $\mathrm{C}$ failed to detect any pathogenic segregating mutation, however, we didn't check for regulatory mutations or large deletions. Moreover, the two affected siblings in this family had ataxia and oculomotor apraxia with no cerebellar atrophy and normal tendon reflexes and they may belong to a similar overlapping form of ataxia. None of our patients has features suggestive of ataxia 
telangiectasia. Particularly there was no repeated infection, tumor appearance or changes in immunoglobulins in these families.

We screened nine affected individuals from 4 families with ataxia and oculomotor apraxia for mutations in the reported genes APTX, SETX and MRE11 and identified a novel truncating mutation in SETX gene in one family and a previously reported missense mutation in MRE11 gene in two families.

\section{Conclusion}

Identification of a novel truncating mutation in SETX gene in a Saudi family with AOA2 and the common reported mutation W210C in MRE11 in two families with ataxia and oculomotor apraxia supports the involvement of these genes in the disease progression. Lack of mutations in APTX, SETX and MRE11 genes in the third family diagnosed with ataxia and oculomotor apraxia and no cerebellar atrophy suggests the involvement of another mechanism for the development of this disorder.

\section{Acknowledgements}

The Authors would like to thank, Mohamad Rajab, Shamsa Al Enazi, Mashael Zaidi, and Dorota Moniez for their help with DNA Sequencing; Batoul Baz and Salma Wakil for their help in processing the 10K affymetrix chip. This work was supported and approved by King Faisal Specialist Hospital and Research Center (KFSH\&RC) Project number RAC \#2050036.

\section{Author details}

'Department of Neurosciences, King Faisal Specialist Hospital and Research Center. P.O box 3354 Riaydh 11211 Saudi Arabia. ${ }^{2}$ Department of Genetics, King Faisal Specialist Hospital and Research Center. P.O box 3354 Riyadh 11211 Saudi Arabia.

\section{Authors' contributions}

SB \& TK were responsible for patient's phenotyping and sample collection. $J S, L S, D K$ participated in gene amplification and sequence analysis, NT and SB participated in the design of the study. NT drafted the manuscript. Both SB and JS participated in editing the manuscript and contributed equality to the manuscript. All authors read and approved the manuscript.

\section{Competing interests}

The authors declare that they have no competing interests.

Received: 4 August 2010 Accepted: 16 February 2011 Published: 16 February 2011

\section{References}

1. Gascon GG, Abdo N, Sigut D, Hemidan A, Hannan MA: Ataxia-oculomotor apraxia syndrome. J Child Neurol 1995, 10:118-122.

2. Le Ber I, Moreira MC, Rivaud-Pechoux S, Chamayou C, Ochsner F, Kuntzer T, Tardieu M, Said G, Habert MO, Demarquay G, et al: Cerebellar ataxia with oculomotor apraxia type 1: clinical and genetic studies. Brain 2003, 126:2761-2772.

3. Shimazaki H, Takiyama Y, Sakoe K, Ikeguchi K, Niijima K, Kaneko J, Namekawa M, Ogawa T, Date H, Tsuji S, et al: Early-onset ataxia with ocular motor apraxia and hypoalbuminemia: the aprataxin gene mutations. Neurology 2002, 59:590-595.

4. Koenig M: Rare forms of autosomal recessive neurodegenerative ataxia. Semin Pediatr Neurol 2003, 10:183-192.

5. Fernet $M$, Gribaa M, Salih MA, Seidahmed MZ, Hall J, Koenig M: Identification and functional consequences of a novel MRE11 mutation affecting 10 Saudi Arabian patients with the ataxia telangiectasia-like disorder. Hum Mol Genet 2005, 14:307-318.

6. Amouri R, Moreira MC, Zouari M, El Euch G, Barhoumi C, Kefi M, Belal S, Koenig M, Hentati F: Aprataxin gene mutations in Tunisian families. Neurology 2004, 63:928-929.

7. Date H, Onodera O, Tanaka H, Iwabuchi K, Uekawa K, Igarashi S, Koike R, Hiroi T, Yuasa T, Awaya Y, et al: Early-onset ataxia with ocular motor apraxia and hypoalbuminemia is caused by mutations in a new HIT superfamily gene. Nat Genet 2001, 29:184-188.

8. Moreira MC, Barbot C, Tachi N, Kozuka N, Uchida E, Gibson T, Mendonca P, Costa M, Barros J, Yanagisawa T, et al: The gene mutated in ataxia-ocular apraxia 1 encodes the new HIT/Zn-finger protein aprataxin. Nat Genet 2001, 29:189-193.

9. Yoon G, Westmacott R, MacMillan L, Quercia N, Koutsou P, Georghiou A, Christodoulou K, Banwell B: Complete deletion of the aprataxin gene: ataxia with oculomotor apraxia type 1 with severe phenotype and cognitive deficit. J Neurol Neurosurg Psychiatry 2008, 79:234-236.

10. Gueven N, Becherel OJ, Kijas AW, Chen P, Howe O, Rudolph JH, Gatti R, Date H, Onodera O, Taucher-Scholz G, Lavin MF: Aprataxin, a novel protein that protects against genotoxic stress. Hum Mol Genet 2004, 13:1081-1093.

11. Seidle HF, Bieganowski P, Brenner C: Disease-associated mutations inactivate AMP-lysine hydrolase activity of Aprataxin. J Biol Chem 2005, 280:20927-20931.

12. Moreira MC, Klur S, Watanabe M, Nemeth AH, Le Ber I, Moniz JC, Tranchant C, Aubourg P, Tazir M, Schols L, et al: Senataxin, the ortholog of a yeast RNA helicase, is mutant in ataxia-ocular apraxia 2. Nat Genet 2004, 36:225-227.

13. Fogel BL, Perlman $\mathrm{S}$ : Novel mutations in the senataxin DNA/RNA helicase domain in ataxia with oculomotor apraxia 2. Neurology 2006, 67:2083-2084.

14. Chen $\mathrm{YZ}$, Bennett $\mathrm{CL}$, Huynh HM, Blair IP, Puls I, Irobi J, Dierick I, Abel A, Kennerson ML, Rabin BA, et al: DNA/RNA helicase gene mutations in a form of juvenile amyotrophic lateral sclerosis (ALS4). Am J Hum Genet 2004, 74:1128-1135.

15. Bassuk AG, Chen YZ, Batish SD, Nagan N, Opal P, Chance PF, Bennett CL: In cis autosomal dominant mutation of Senataxin associated with tremor/ ataxia syndrome. Neurogenetics 2007, 8:45-49.

16. Suraweera A, Becherel OJ, Chen P, Rundle N, Woods R, Nakamura J, Gatei M, Criscuolo C, Filla A, Chessa L, et al: Senataxin, defective in ataxia oculomotor apraxia type 2 , is involved in the defense against oxidative DNA damage. J Cell Biol 2007, 177:969-979.

17. Delia D, Piane M, Buscemi G, Savio C, Palmeri S, Lulli P, Carlessi L, Fontanella E, Chessa L: MRE11 mutations and impaired ATM-dependent responses in an Italian family with ataxia-telangiectasia-like disorder. Hum Mol Genet 2004, 13:2155-2163.

18. Pitts SA, Kullar HS, Stankovic T, Stewart GS, Last Jl, Bedenham T, Armstrong SJ, Piane M, Chessa L, Taylor AM, Byrd PJ: hMRE11: genomic structure and a null mutation identified in a transcript protected from nonsense-mediated mRNA decay. Hum Mol Genet 2001, 10:1155-1162.

19. Takashima H: [Molecular genetics of inherited neuropathies]. Rinsho Shinkeigaku 2006, 46:1-18.

20. De Sandre-Giovannoli A, Chaouch M, Kozlov S, Vallat JM, Tazir M, Kassouri N, Szepetowski P, Hammadouche T, Vandenberghe A, Stewart CL, et al: Homozygous defects in LMNA, encoding lamin A/C nuclearenvelope proteins, cause autosomal recessive axonal neuropathy in human (Charcot-Marie-Tooth disorder type 2) and mouse. Am J Hum Genet 2002, 70:726-736.

21. Bomont P, Cavalier L, Blondeau F, Ben Hamida C, Belal S, Tazir M, Demir E, Topaloglu H, Korinthenberg R, Tuysuz B, et al: The gene encoding gigaxonin, a new member of the cytoskeletal BTB/kelch repeat family, is mutated in giant axonal neuropathy. Nat Genet 2000, 26:370-374.

22. Liu W, Narayanan V: Ataxia with oculomotor apraxia. Semin Pediatr Neurol 2008, 15:216-220.

23. Suraweera A, Lim Y, Woods R, Birrell GW, Nasim T, Becherel OJ, Lavin MF: Functional role for senataxin, defective in ataxia oculomotor apraxia type 2, in transcriptional regulation. Hum Mol Genet 2009.

24. Habeck M, Zuhlke C, Bentele KH, Unkelbach S, Kress W, Burk K, Schwinger E, Hellenbroich Y: Aprataxin mutations are a rare cause of early onset ataxia in Germany. J Neurol 2004, 251:591-594.

25. Criscuolo C, Mancini P, Sacca F, De Michele G, Monticelli A, Santoro L, Scarano V, Banfi S, Filla A: Ataxia with oculomotor apraxia type 1 in 
Southern Italy: late onset and variable phenotype. Neurology 2004, 63:2173-2175.

26. Tsao CY, Paulson G: Type 1 ataxia with oculomotor apraxia with aprataxin gene mutations in two American children. J Child Neurol 2005, 20:619-620.

27. Quinzii CM, Kattah AG, Naini A, Akman HO, Mootha VK, DiMauro S, Hirano M: Coenzyme Q deficiency and cerebellar ataxia associated with an aprataxin mutation. Neurology 2005, 64:539-541.

28. Stewart GS, Maser RS, Stankovic T, Bressan DA, Kaplan MI, Jaspers NG Raams A, Byrd PJ, Petrini JH, Taylor AM: The DNA double-strand break repair gene hMRE11 is mutated in individuals with an ataxiatelangiectasia-like disorder. Cell 1999, 99:577-587.

29. Paull TT, Lee JH: The Mre11/Rad50/Nbs 1 complex and its role as a DNA double-strand break sensor for ATM. Cell Cycle 2005, 4:737-740.

Pre-publication history

The pre-publication history for this paper can be accessed here: http://www.biomedcentral.com/1471-2350/12/27/prepub

doi:10.1186/1471-2350-12-27

Cite this article as: Bohlega et al: Clinical and Molecular

Characterization of Ataxia with Oculomotor Apraxia Patients In Saudi Arabia. BMC Medical Genetics 2011 12:27.

\section{Submit your next manuscript to BioMed Central} and take full advantage of:

- Convenient online submission

- Thorough peer review

- No space constraints or color figure charges

- Immediate publication on acceptance

- Inclusion in PubMed, CAS, Scopus and Google Scholar

- Research which is freely available for redistribution

Submit your manuscript at www.biomedcentral.com/submit 